\title{
Upaya Meningkatkan Hasil Belajar Peserta Didik dengan Menggunakan Rancang Bangun Lego pada Pemahaman Konsep Titik Berat
}

\section{Efforts to Improve Learning Outcomes of the Students by using a Lego Design on Understanding the Weight Point Concept}

\author{
Rr. Dyah Endah Rukmi \\ SMA Negeri 21 Bandung, Bandung, Jawa Barat, Indonesia \\ calvinpancasakti@gmail.com
}

Naskah diterima tanggal 02/06/2019, direvisi akhir tanggal 24/06/2019, disetujui tanggal 31/07/2019

\begin{abstract}
Abstrak
Penelitian Tindakan Kelas (PTK) yang tertuang dalam laporan ini ingin melihat bagaimana minat, pemahanan, terampil, tanggung jawab peserta didik dalam mengikuti kegiatan belajar mengajar dan juga bagaimana hasil pembelajaran peserta didik dalam memahami konsep Titik Berat dengan menggunakan model rancang bangun lego. Tahapan PTK bersifat refleksi tindakan dengan pola proses "Perencanaan - Tindakan - Observasi - Refleksi". Sampel yang diambil dalam penelitian tindakan kelas ini adalah satu kelas XI MIPA-2 terdiri dari 34 siswa. Dari 34 peserta didik tersebut diberikan lembar kegiatan peserta didik untuk melakukan kegiatan sesuai instruksi yang tertuang dalam LKS tersebut. Hasil yang diperoleh dari penelitian dengan menggunakan metode pengajaran yang tepat yaitu menggunakan model rancang bangun lego jadi lebih menarik dan tidak cenderung membosankan siswa, hal ini dapat dilihat dari hasil perolehan aktivitas peserta didik dari 2.24 pada kegiatan siklus ke 1 naik menjadi 3.18 pada siklus ke 3. Pemahaman konsep titik berat dengan menggunakan model rancang bangun lego diperoleh hasil sebesar 76.12 pada siklus 1 naik menjadi 94.44 pada siklus 3, hal ini dapat dikatakan bahwa ada keterkaitan yang signifikan antara perolehan hasil praktik dengan aktivitas peserta didik, sehingga perolehan pemahaman konsep yang baik dan benar dapat tercapai. Sedangkan hasil belajar peserta didik adanya kenaikan sebesar 83.24, hal ini dapat dikatakan bahwa daya serap peserta didik baik karena dapat dibuktikan dengan hasil ketuntasan peserta didik yang sudah memenuhi standar ketuntasan yaitu 72 .
\end{abstract}

Kata kunci: hasil belajar, titik berat rancang bangun lego.

\section{Abstract}

The Classroom Action Research contained in this report wants to see how interest, understanding, skillfulness, responsibility of students in participating in teaching and learning activities and also the learning outcomes of students in understanding the concept of Heavy Points by using design models. actions with process patterns "Planning - Actions - Observation - Reflection". Samples taken in this classroom action research are one class XI MIPA-2 consisting of 34 students. From 34 students, students are given an activity sheet to carry out activities according to instructions stated in the LKS. The results obtained from the research using the right teaching method that is using the Lego design model become more interesting and do not tend to boring students, this can be seen from the results of the activities of students from 2.24 of cycle 1 up to 3.18 of cycle 3 . The understanding of the concept of gravity by using the Lego design model results obtained at 76.12 in cycle 1 rose to 94.44 in cycle 3, it can be said that there is a significant relationship between the acquisition of practice results with the activities of students, so that the acquisition of understanding concepts good and true can be achieved. While the learning outcomes of students have an increase of 83.24, it can be said that the absorption of students is good because it can be proven by the results of completeness of students who have met the standard of completeness, namely 72 Keywords: learning outcomes, weight point, lego build design. 


\section{PENDAHULUAN}

Image Fisika "sulit dan kurang menarik" dikalangan peserta didik merupakan mata pelajaran yang sangat kurang diminati peserta didik dikarenakan nilai yang mereka peroleh kebanyakan relatif kecil, bahkan dibenak peserta didik pembelajaran fisika itu pembelajaran yang selalu disajikan dengan rumus-rumus yang sangat membosankan, sehingga pembelajaran fisika dirasa kurang menarik dan pemahaman siswa masih kurang. Adapun pemahaman menurut Sanjaya (2009) merupakan kemampuan siswa yang berupa penguasaan materi pelajaran, dimana siswa tidak hanya mengingat beberapa konsep saja, namun mampu menjelaskan kembali dan menerapkannya.

Untuk mengatasi semua ini maka tugas seorang guru merumuskan, mencari formulasi yang diinginkan peserta didik dalam mengatasi image tersebut agar tidak melekat dipikiran dan benak siswa, yaitu dengan cara bermain dengan melakukan praktik yaitu menyusun model rancang bangun lego sederhana. Kegiatan praktikum atau percobaan fisika merupakan kegiatan yang seharusnya dilakukan sebagai bagian yang terintegrasi dalam pembelajaran fisika. Melalui kegiatan ini peserta didik diharapkan mengalami suatu proses untuk memahami konsep-konsep fisika melalui pengamatannya terhadap gejala-gejala alam sebagai selayaknya seorang ilmuan melakukan serangkaian kegiatan ilmiah dalam menemukan suatu teori tentang gejala alam, melalui pengamatan terhadap gejalagejala alam.

Model pembelajaran yang digunakan guru, guru harus memperhatikan apakah dengan menggunakan model rancang bangun lego pengajaran menjadi efektif dan efisien. Hal ini sesuai dengan pendapat Sudjana (1989) bahwa pembelajaran tidak sematamata berorientasi pada hasil (product) tetapi berorientasi juga pada proses (process) dengan harapan makin tinggi hasil yang dicapai. Pernyataan ini memberikan alternatif bahwa penggunaan model pembelajaran yang sesuai dapat mengoptimalkan hasil belajar yang diperoleh. Kegiatan ini juga dapat melatih peserta didik untuk berfikir kreatif, meningkatkan minat, dan lebih cepat tanggap dalam mengambil sesuatu keputusan. Adapun meningkatkan minat merupakan suatu ide yang memungkinkan siswa untuk mempu menjeleaskan serta mengelompokkannya (Ruseffendi, 1998). Model pembelajaran memfokuskan pada kegiatan untuk memberdayakan siswa dalam mengintegrasikan teori, menerapkan pengetahuan dan untuk menumbuhkembangkan keterampilan untuk menemukan solusi (Arends, 2007; Schmit \& Moust, 2000; Savery, 2006).

Hasil belajar merupakan aktivitas yang berkaitan dengan penataan informasi, reorganisasi perceptual, proses internal dan perubahan persepsi serta pemahaman yang tidak selalu berbentuk tingkah laku yang dapat diamati dan diukur. Pandangan ini menunjukan bahwa setiap orang memiliki pengetahuan dan pengalaman yang telah tertata dalam bentuk struktur koqnitif yang telah dimilikinya.

Gagne membagi hasil belajar dalam tiga macam yaitu : informasi verbal, keterampilan intelektual, strategi koqnitif, sikap dan keterampilan motorik (Dahar, 1986). Sebagaimana saat siswa menemukan sebuah solusi terhadap suatu masalah, saat itulah sesungguhnya siswa menyiapkan mental dan kemampuan untuk memahami konsep yang telah diajarkan (Aunurrahman, 2009; Zohar, 1994; Slameto, 2003).

Kemampuan yang mencakup untuk masing-masing hasil belajar dapat dijelaskan sebagai berikut :

1. Informasi Verbal, merupakan informasi yang diperoleh dari kata yang diucapkan orang, meliputi nama, fakta, prinsip dan generalisasi.

2. Keterampilan Intelektual, meliputi kemampuan untuk membedakan, menunjukan suatu konsep dan dapat melakukan sesuatu sesuai dengan aturan.

3. Strategi Koqnitif, penggunaannya bagi peserta didik terutama pada saat memikirkan sesuatu yang telah dipelajari dan memecahkan masalah secara kreatif.

4. Sikap, merupakan pembawaan yang 
dapat dipelajari dan dapat mempengaruhi tingkah laku terhadap benda-benda, kejadian atau kehidupan.

5. Sekumpulan sikap yang penting adalah sikap yang ditunjukan pada saat berhubungan dengan orang lain. Gagne juga memikirkan sasaran kondisi-kondisi untuk belajar sikap atau sikap sosial. Sebagai contoh sikap sosial dapat dipelajari dengan meminta perhatian peserta didik dalam melaksanakan praktikum.

Dalam suatu proses belajar mengajar penilaian dengan mengukur sejauh mana kompetensi dasar telah dicapai. Kompetensi dasar ini mempunyai rumusan kemampuan yang diharapkan dimiliki peserta didik sebagai hasil dari mengikuti suatu program pengajaran. Dengan demikian penilaian suatu kegiatan belajar mengajar adalah untuk mengetahui kemampuan apakah yang dimiliki peserta didik setelah kegiatan belajar mengajar berakhir.

Model adalah seorang atau sesuatu dengan sifat-sifat yang sangat baik yang seharusnya ditiru oleh orang lain. Example adalah sesuatu baik atau buruk, yang dapat ditiru. Sementara "pattern" dapat diartikan sebagai sebuah model, rencana dan sebagainya yang harus diikuti dengan persis. Penjelasan yang hampir sama disampaikan oleh Badudu dan Zain (1996: 904) bahwa model memiliki arti yang sama dengan contoh, acuan dan pola.

Model pembelajaran merupakan suatu pola pendekatan menyeluruh yang digunakan untuk mendesain pengajaran. Model yang ditetapkan oleh guru bertujuan untuk mempermudah proses belajar dalam diri peserta didik. Dalam pembelajarannya peserta didik diajak untuk memahami konsep-konsep abstrak untuk diaplikasikan dalam kehidupan sehari-hari

Penjelasan di atas menunjukkan bahwa model mengandung banyak arti, bergantung dari sudut mana memandangnya. Tetapi yang pasti, "model" yang dikehendaki dalam konteks penelitian ini, lebih mendekati "example", design atau "pat-tern", yaitu sebuah pola yang dapat dijadilan contoh atau rancangan yang dapat dijadikan acuan atau pedoman dalam melakukan sesuatu.
Model rancang bangun lego yang dimaksud dalam pembelajaran ini adalah suatu rancangan,desain pola dari bahanbahan kayu dan mika yang dirancang sedemikian rupa sehingga dapat disusun seperti alat permainan yang akan dijadikan objek atau dapat ditentukan beberapa titik beratnya dari pemahaman konsep Titik Berat sesuai tujuan pembelajaran yang hendak dicapai.

\section{METODE PENELITIAN}

Penelitian ini dilaksanakan di kelas XI MIPA-2 SMA Negeri 21 Bandung yang berjumlah 34 siswa, terdiri dari 10 siswa laki-laki dan 24 siswa perempuan. Penelitian ini dilaksanakan pada semester ganjil bulan Agustus minggu kedua sampai dengan minggu kesatu bulan september tahun 2018. Penentuan waktu penelitian ini dilaksanakan dengan berpedoman pada kalender sekolah serta jadwal kelas XI MIPA- 2.

Penelitian ini bersifat penelitian tindakan kelas (PTK),karena hasil penelitian ini memberikan kerangka kerja yang teratur kepadapemecahan masalah praktis. Penelitian tindakan kelas juga bersifat empiris, artinya dalam penelitian mengandalkan observasi nyata dan data perilaku.Rancangan yang digunakan agar pelaksanaan kegiatan Penelitian Tindakan Kelas sesuai dengan rancangan yang telah ditetapkan, perlu kiranya dikemukakan tahapan-tahapan yang ditempuh dalam pelaksanaan penelitian sebagai berikut perencanaan, tindakan, observasi, and refleksi.

Adapun tahapan-tahapan tersebut dijelaskan sebagai berikut:

1. Tahapan Perencanaan.

Sebelum penelitian tindakan kelas dilaksanakan, peneliti menyusun instrumen penelitian yang akan digunakan untuk memberi perlakuan dalam PTK, yaitu RPP dengan kompetensi dasar (KD) yaitu: Titik Berat. Selain itu disusun pula perangkat pembelajaran yang meliputi: lembar kegiatan peserta didik (LKS), lembar Soal Pre-test, lembar pengamatan aktivitas peserta didik dan lembar pengamatan responden guru.

2. Tahapan Tindakan. 
Pada tahapan Tindakan ini, peneliti memulai dengan melakukan apersepsi dengan menggunakan pre-test untuk mengetahui sejauhmana pemahaman peserta didik tentang materi sebelumnya dengan demikian peneliti dapat melakukan tindakan sesuai langkah-langkah pembelajaran yang telah dipersiapkan.

\section{Tahapan Observasi}

Pada tahapan ini peneliti bersama mitra kerja mengamati proses belajar mengajar bertujuan dapat menilai kekurangan dan kelebihan peneliti dalam memberikan tindakan kepada siswa.

4. Tahapan Refleksi

Pada tahapan Refleksi ini peneliti merevisi kembali kekurangan dan keberhasilan baik dari hasil belajar peserta didik maupun hasil pengamatan yang dilakukan oleh pengamat(teman-sejawat ) maupun metode yang dilakukan peneliti untuk melakukan tindakan pada PBM, sehingga pada perlakuan tindakan berikutnya dapat dilaksanakan dengan lebih baik lagi. beberapa siklus yang membutuhkan proses belajar mengajar yang lebih efektif.

Pelaksanaan pengumpulan data dilakukan sebelum dan setelah para peserta didik mendapatkan KBM di kelas dengan menyelesaikan soal-soal yang telah disediakan .Pelaksanaan KBM dilakukan terhadap 36 peserta didik secara klasikal di dalam kelas .Data penelitian ini dikumpulkan dengan seperangkat instrumen yaitu tes tertulis dan lembar observasi.

Analisis data yang digunakan dalam PTK adalah deskriptif kualitatif dan kuantitatif. Pendekatan kualitatif digunakan untuk menggambarkan kegiatan dan aktivitas peserta didik selama PBM berdasarkan perubahan setiap siklus. Sedangkan secara kuantitatif digunakan untuk melihat hasil belajar peserta didik berapa besar ketuntasan belajar peserta didik dalam memahami konsep pokok bahasan titik berat.

\section{HASIL DAN PEMBAHASAN}

\subsection{Hasil}

Deskripsi hasil penelitian tindakan kelas merupakan gambaran umum masing- masing kegiatan yang telah dilakukan. Dalam penelitian ini pembelajaran dilakukan dalam empat siklus. Secara keseluruhan diperoleh hasil pemahaman konsep Titik Berat sebagai berikut:

1. Siklus Pertama

Siklus pertama terdiri dari empat tahap, yaitu : perencanaan, tindakan, observasi, dan refleksi.

a. Perencanaan

Peneliti melakukan analisis kurikulum untuk menentukan standar kompetensi dan kompetensi dasar yang akan disampaikan ke peserta didik dengan menampilkan presentasi dengan menggunakan power point, membuat rencana pelaksanaan pembelajaran, membuat instrumen yang digunakan dalam siklus PTK, menyusun alat evaluasi pembelajaran.

b. Tindakan

Pada saat awal siklus pertama pelaksanaan telah sesuai dengan rencana. Hal ini disebabkan; 1) Peserta didik belum terbiasa belajar dengan kondisi ada guru lebih dari satu berada di dalam kelas. 2) Peserta didik belum seluruhnya memahami konsep titik berat dengan benar. Untuk mengatasi masalah di atas dilakukan upaya, yaitu guru menjelaskan secara intensif kepada peserta didik bagaimana pembelajaran dengan metode praktik yang tidak membosankan dengan menggunakan model rancang bangun lego yang sudah tersedia. Pada akhir siklus pertama dari hasil pengamatan guru bersama teman sejawat dapat disimpulakan bahwa peserta didik sudah mulai terbiasa belajar dalam kondisi ada beberapa guru di dalam kelas, walaupun keaktifan peserta didik masih kurang kondusif.

c. Obervasi dan Evaluasi

Hasil pengamatan aktivitas peserta didik dalam siklus pertama diperoleh rata-rata 2.24 dari perolehan aktivtas peserta didik dalam mengikuti PBM dengan kriteria sangat cukup baik, sedangkan hasil pengamatan aktivitas guru dalam PBM oleh responden guru 
dengan perolehan jumlah rata-rata kegiatan sebesar 2.4 dengan kriteria cukup baik. Perolehan hasil belajar peserta didik sebelum diberi tindakan 48,8 dan setelah diberi tindakan berupa praktik menjadi 76.12 .

d. Refleksi

Adapun kegagalan dan keberhasilan dalam siklus pertama yaitu guru belum dapat menggiring peserta didik untuk bertanya dan berkomunikasi antar peserta didik dalam menaggapi diskusi dengan baik. Untuk memperbaiki pembelajaran pada siklus pertama maka,guru merevisi kembali agar pembelajaran pada siklus berikutnya diupayakan keberhasilan peserta didik dapat meningkat.

2. Siklus Kedua

a. Perencanaan

Rencana pada siklus ke dua berdasarkan tindakan siklus ke satu yaitu; 1) Mempersiapkan RPP, skenario pembelajaran juga instrumen lainnya yang terkait; 2) Memberi motivasi kepada peserta didik agar lebih aktif lagi dalam pembelajaran; 3) Lebih intensif dalam membimbing peserta didik yang mengalami kesulitan; 4) Memberi penghargaan atau pengakuan kepada peserta didik dalam menanggapi dan menjawab pertanyaan dari tiap siswa.

b. Tindakan

Suasana pembelajaran sudah lebih kondusif, peserta didik dalam satu kelompok saling membantu dalam penguasaan materi pelajaran yang diberikan melalui tanya jawab atau diskusi antar sesama anggota kelompok, sehingga suasana yang efektif dan menyenangkan sudah tercipta.

c. Observasi dan Evaluasi

Pada siklus 2 dilakukan dengan cara yang sama, tetapi presentasi yang dilakukan tidak menggunakan power point dikarenakan terjadi pemadaman listrik sehingga perolehan hasil belajar peserta didik berupa kegiatan praktik sebesar 87.62 dari hasil belajar pada siklus ke 2, dengan demikian ada kenaikan 11,5 poin dari kegiatan siklus kesatu .Sehingga dari hasil uraian di atas dapat dikatakan telah memenuhi kriteria ketuntasan minimum yaitu 72 .

Dari hasil rata-rata pengamatan yang dilakukan mitra kerja dari siklus 1 dan 2 ternyata ada perubahan aktivitas peserta didik dari 2.24 yang awalnya kurang komunikatif menjadi jauh lebih baik yaitu sebesar 2.59 ini berarti aktivitas menunjukan kriteria cukup baik walaupun dalam hal merespon setiap pertanyaan guru ada penurunan. Hal ini dapat terjadi dimungkinkan peserta didik; 1) Sebelum belajar fisika ada mata pelajaran lain yang ulangan; 2) Kecewa karena terjadi pemadaman listrik yang mendadak. Sedangkan dari hasil responden guru dalam pengamatan PMB sebesar 2.93 dengan kriteria baik, ini berarti ada kenaikan didalam KBM.

d. Refleksi

Adapun keberhasilan siklus ke 2 adalah aktivitas dalam PBM sudah lebih baik.Peserta didik mampu membangun kerjasama,berpartisipasi dalam kegiatan dan tepat waktu dalam pelaksanaan serta mampu mempresentasikan hasil kerja dengan kelompok untuk memahami tugas yang diberikan guru. Hal ini dapat dilihat dari data observasi pengamat terhadap aktivitas peserta didik meningkat dari 2.24 pada siklus ke 1 menjadi 2.59 pada siklus ke 2 . Sedangkan hasil nilai praktikum peserta didik pada siklus kedua meningkat dari 48.8 sebelum diberi tindakan menjadi 87.62.

3. Siklus Ketiga

a. Perencanaan

Rencana pada siklus ketiga berdasarkan tindakan siklus kedua yaitu; 1) Mempersiapkan RPP, skenario pembelajaran juga instrumen lainnya yang terkait; 2) Memberi motivasi kepada kelompok agar lebih 
aktif lagi dalam pembelajaran; 3) Lebih intensif dalam membimbing kelompok yang mengalami kesulitan; 4) Memberi penghargaan atau pengakuan kepada peserta didik dalam menanggapi dan menjawab pertanyaan dari tiap kelompok.

b. Tindakan

Suasana pembelajaran sudah lebih kondusif, peserta didik dalam satu kelompok saling membantu dalam penguasaan materi pelajaran yang diberikan melalui praktik, tanya jawab atau diskusi antar sesama peserta didik atau anggota kelompok, sehingga suasana yang efektif dan menyenangkan sudah tercipta.

c. Observasi dan Evaluasi

Pada siklus 3 dilakukan dengan cara yang sama, peserta didik dapat langsung melakukan kegiatan praktikum, sehingga perolehan hasil praktikum peserta didik naik sebesar 18.32 poin dari hasil praktik pada siklus ke 1, naik 45.64 poin dari hasil sebelum diberi tindakan pada siklus ke 1. Adapun hasil nilai dari ulangan harian sebesar 83,24 telah memenuhi kriteria ketuntasan minimum yaitu 72 . Dari hasil rata-rata pengamatan yang dilakukan mitra kerja dari siklus 2 dan 3 ternyata ada perubahan aktivitas peserta didik dari 2.59 yang awalnya kurang komunikatif menjadi jauh lebih baik yaitu sebesar 3.18 ini berarti ada kenaikan sebesar 0.59 poin. Sedangkan dari hasil responden guru dalam pengamatan KBM dari siklus kedua sebesar 2.93 dengan kriteria baik menjadi 3.47 dengan kriteria sangat baik, ini berarti ada kenaikan didalam pembelajaran sebesar 0.54 poin.

d. Refleksi

Adapun keberhasilan siklus ke 3 adalah aktivitas dalam PBM sudah baik.Peserta didik mampu membangun kerjasama,berpartisipasi dalam kegiatan dan tepat waktu dalam pelaksanaan serta mampu mempresentasikan hasil kerja dengan kelompok untuk memahami tugas yang diberikan guru.Hal ini dapat dilihat dari data observasi pengamat terhadap aktivitas peserta didik meningkat dari siklus kedua ke siklus ketiga. Sedangkan hasil nilai praktikum peserta didik pada siklus ketiga juga meningkat.

\subsection{Pembahasan}

Deskripsi hasil penelitian merupakan gambaran umum masing-masing kegitan yang dilakukan, serta hasil pengamatan yang terekam terhadap data dan analisis data penilaian. Hasil perolehan observasi aktivitas peserta didik dan guru yang diamati oleh mitra kerja.

Tabel 1. Aktivitas peserta didik dalam KBM

\begin{tabular}{|c|c|c|c|c|c|c|c|c|c|c|c|c|c|c|c|c|}
\hline \multirow{4}{*}{ NO } & \multirow{4}{*}{ KETERANGAN } & \multicolumn{15}{|c|}{ SIKLUS KE } \\
\hline & & \multirow{2}{*}{\multicolumn{4}{|c|}{$\begin{array}{c}1 \\
\text { SKOR }\end{array}$}} & \multicolumn{4}{|c|}{2} & \multirow{2}{*}{\multicolumn{4}{|c|}{$\begin{array}{c}3 \\
\text { SKOR }\end{array}$}} & \multicolumn{3}{|c|}{ JUMLAH } \\
\hline & & & & & & \multicolumn{4}{|c|}{ SKOR } & & & & & \multirow[t]{2}{*}{1} & \multirow[t]{2}{*}{2} & \multirow[t]{2}{*}{3} \\
\hline & & 1 & 2 & 3 & 4 & 1 & 2 & 3 & 4 & 1 & 2 & 3 & 4 & & & \\
\hline 1 & MINAT & & 4 & 2 & & & 3 & 2 & 1 & & & 2 & 4 & 14 & 16 & 22 \\
\hline 2 & PEMAHAMAN & & 4 & 1 & 1 & & 3 & 2 & 1 & & & 3 & 3 & 15 & 16 & 21 \\
\hline 3 & JUJUR & & 2 & 3 & 1 & & & 4 & 2 & & & 3 & 3 & 20 & 20 & 21 \\
\hline 4 & TELITI & & 3 & 2 & 1 & & & 5 & 1 & & & 3 & 3 & 13 & 19 & 21 \\
\hline \multirow[t]{3}{*}{5} & TANGGUNG JAWAB & & 4 & 2 & & & 2 & 3 & 1 & & & 1 & 5 & 14 & 17 & 23 \\
\hline & JUMLAH & & & & & & & & & & & & & 76 & 88 & 108 \\
\hline & RATA-RATA & & & & & & & & & & & & & 2.24 & 2.59 & 3.18 \\
\hline
\end{tabular}




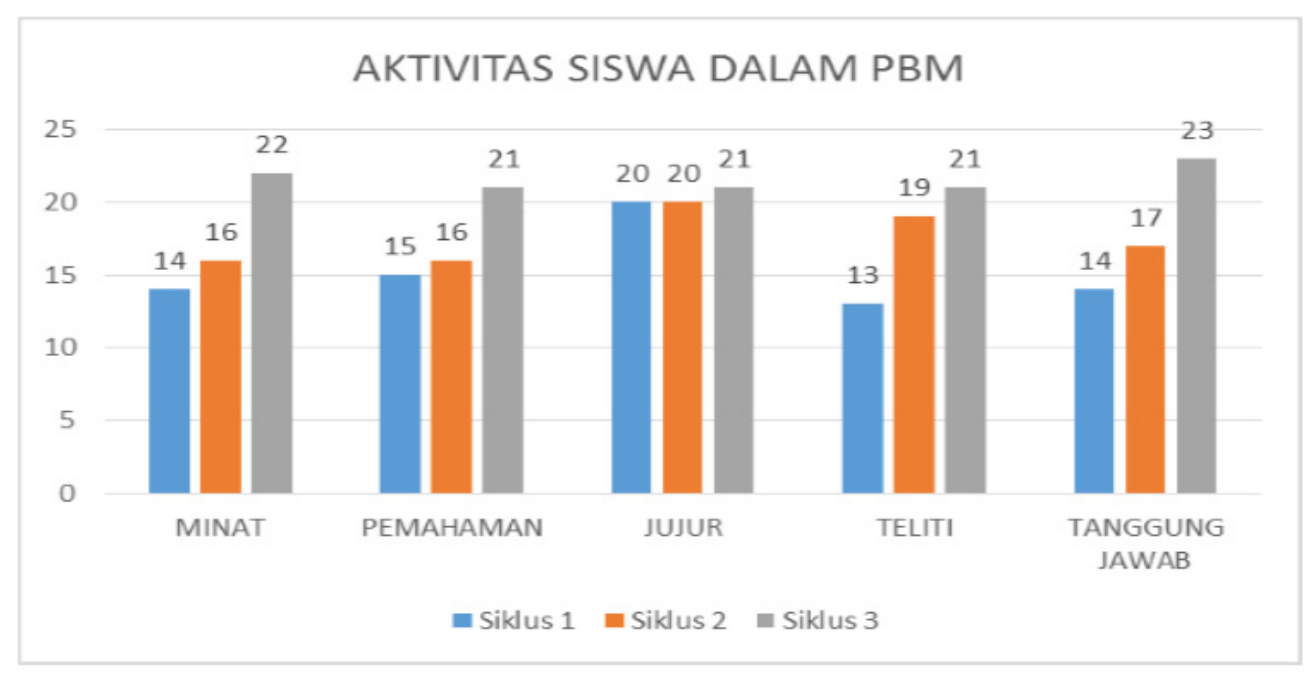

Gambar 1. Aktivitas peserta didik dalam PBM

Dari hasil pengamatan kolaborator pada tebel 1 dan gambar 1 , memberikan gambaran bahwa pada siklus ke 1 minat peserta didik masih perlu ditingkatkan maka peneliti merevisi tindakan 1 untuk membenahi kegiatan pada siklus ke 2 . Hasil pengamatan kolaborator pada siklus ke 2 ada temuan menunjukan bahwa terjadi penurunan mengenai ketelitian dan tanggung jawab pada peserta didik dalam melakukan kegiatan praktik. Sedangkan pada siklus ketiga sikap tanggung jawab peserta didik sudah dapat dipertanggung jawabkan.

Dari hasil pengamatan teman sejawat mengenai responden guru menunjukan kriteria membaik dan dapat dilihat pada tabel 2 yang merupakan data perolehan hasil pengamatan responden guru dalam pembelajaran.

Tabel 2. Data pengamatan PBM responden guru

\begin{tabular}{|c|c|c|c|c|c|c|c|c|c|c|c|c|c|}
\hline \multirow{3}{*}{ NO } & \multirow{3}{*}{ JENIS KEGIATAN } & \multicolumn{12}{|c|}{ SIKLUS KE } \\
\hline & & \multicolumn{4}{|c|}{1} & \multicolumn{4}{|c|}{2} & \multicolumn{4}{|c|}{3} \\
\hline & & 1 & 2 & 3 & 4 & 1 & 2 & 3 & 4 & 1 & 2 & 3 & 4 \\
\hline 1 & Apersepsi & & $\sqrt{ }$ & & & & & $\sqrt{ }$ & & & & & $\sqrt{ }$ \\
\hline 2 & Penjelasan Materi & & & $\sqrt{ }$ & & & & $\sqrt{ }$ & & & & $\sqrt{ }$ & \\
\hline 3 & Penjelasan Metode Pembelajaran & & & $\sqrt{ }$ & & & & $\sqrt{ }$ & & & & $\sqrt{ }$ & \\
\hline 4 & Teknik Pembagian Kelompok & & $\sqrt{ }$ & & & & & $\sqrt{ }$ & & & & $\sqrt{ }$ & \\
\hline 5 & Penguasaan Kelas & & & $\sqrt{ }$ & & & & $\sqrt{ }$ & & & & & $\sqrt{ }$ \\
\hline 6 & Penggunaan Media & & $\sqrt{ }$ & & & & & $\sqrt{ }$ & & & & & $\sqrt{ }$ \\
\hline 7 & Suara & & & $\sqrt{ }$ & & & & & $\sqrt{ }$ & & & & $\sqrt{ }$ \\
\hline 8 & Pengelolaan Kegiatan Diskusi & & $\sqrt{ }$ & & & & & $\sqrt{ }$ & & & & $\sqrt{ }$ & \\
\hline 9 & Bimbingan Pada Kelompok & & & & & & & & & & & & \\
\hline 10 & Pemberian Pertanyaan / kuis & & & $\sqrt{ }$ & & & & $\sqrt{ }$ & & & & & $\sqrt{ }$ \\
\hline 11 & Kemampuan Melakukan Evaluasi & & $\sqrt{ }$ & & & & & $\sqrt{ }$ & & & & & $\sqrt{ }$ \\
\hline 12 & Memberikan Penghargaan individu/kelompok & & & $\sqrt{ }$ & & & $v$ & & & & & & $\sqrt{ }$ \\
\hline 13 & Menentukan nilai individu/kelompok & & $\sqrt{ }$ & & & & & $\sqrt{ }$ & & & & & $\sqrt{ }$ \\
\hline 14 & Menyimpulkan Materi Pembelajaran & & & $\sqrt{ }$ & & & & & $\sqrt{ }$ & & & & $\sqrt{ }$ \\
\hline \multirow[t]{3}{*}{15} & Menutup Pembelajaran & & & $\sqrt{ }$ & & & & & $\sqrt{ }$ & & & & $\sqrt{ }$ \\
\hline & & & 12 & 24 & & & 2 & 30 & 12 & & & 16 & 36 \\
\hline & Rata-Rata Jumlah skor & \multicolumn{4}{|c|}{2.4} & \multicolumn{4}{|c|}{2.93} & \multicolumn{4}{|c|}{3.47} \\
\hline
\end{tabular}

Keterangan Rentang Skor:
$1-1.9$ : Kurang
$1.9-2.0$ : Cukup
$2.1-3 \quad$ : Baik
$3.1-4 \quad$ : Amat Baik 
Tabel 3. Data perolehan nilai

\begin{tabular}{|c|c|c|c|c|c|c|}
\hline \multirow{3}{*}{ NO } & \multirow{3}{*}{ NAMA SISWA } & \multicolumn{5}{|c|}{ NILAI PRAKTIK } \\
\hline & & \multirow{2}{*}{$\begin{array}{c}\text { PRE } \\
\text { TEST }\end{array}$} & \multicolumn{3}{|c|}{ SIKLUS KE } & \multirow{2}{*}{$\begin{array}{c}\text { ULANGAN } \\
\text { HARIAN }\end{array}$} \\
\hline & & & 1 & 2 & 3 & \\
\hline 1 & Afina Nafisah & 60 & 75 & 90 & 95 & 80 \\
\hline 2 & Amira Naja Ghassani & 60 & 75 & 90 & 95 & 80 \\
\hline 3 & Annisa Nur Hidayah & 60 & 75 & 80 & 95 & 80 \\
\hline 4 & Beta Sebastian Gustiwiyana & 60 & 75 & 80 & 95 & 80 \\
\hline 5 & Dani Kurniawan & 60 & 72 & 80 & 95 & 80 \\
\hline 6 & Destya Suci Drupadi & 60 & 75 & 80 & 95 & 80 \\
\hline 7 & Dewi Rahmawaty & 60 & 80 & 93 & 95 & 80 \\
\hline 8 & Diaz Aria Razaky & 60 & 75 & 90 & 95 & 80 \\
\hline 9 & Dinda Anggraeni & 60 & 80 & 90 & 95 & 80 \\
\hline 10 & Dwi Bagia Santosa & 60 & 80 & 90 & 95 & 90 \\
\hline 11 & Elysia Joli Sutjipto & 40 & 75 & 87 & 93 & 90 \\
\hline 12 & Fajriyatur Robi'ah & 40 & 80 & 87 & 93 & 90 \\
\hline 13 & Fauzan Prayoga Nur Fajrin & 40 & 80 & 93 & 95 & 90 \\
\hline 14 & Firda Yunita & 40 & 77 & 90 & 95 & 90 \\
\hline 15 & Ghefira Putri Andaliftya & 40 & 80 & 90 & 95 & 90 \\
\hline 16 & Hanifah Rahmi Nadiyaningsih & 40 & 80 & 90 & 95 & 90 \\
\hline 17 & Isma Azkia Destyani & 40 & 75 & 90 & 95 & 80 \\
\hline 18 & Katleana Safira Widjajanarko & 40 & 75 & 90 & 95 & 80 \\
\hline 19 & Khoirunnisa Nur Fadilah & 40 & 75 & 90 & 95 & 80 \\
\hline 20 & Maulana Hafid Zulkifli & 40 & 75 & 87 & 95 & 80 \\
\hline 21 & Mufidha Auziyati Maryani & 40 & 75 & 87 & 95 & 80 \\
\hline 22 & Muhamad Rizal Fauzan & 60 & 75 & 87 & 95 & 80 \\
\hline 23 & Muhammad Dandy Aulia Suparman & 40 & 75 & 87 & 95 & 80 \\
\hline 24 & Muhammad Saleh Armand Pratama & 60 & 75 & 87 & 90 & 90 \\
\hline 25 & Nabila Azzahra & 60 & 75 & 87 & 90 & 90 \\
\hline 26 & Nurul Aini Yuliawan & 40 & 80 & 90 & 95 & 90 \\
\hline 27 & Putri Firdausya Azzahra & 60 & 80 & 90 & 95 & 90 \\
\hline 28 & Ramdani & 60 & 75 & 90 & 95 & 80 \\
\hline 29 & Regita Kumala Prameswari & 40 & 80 & 90 & 95 & 80 \\
\hline 30 & Riqqah Juniaristin & 40 & 72 & 90 & 95 & 80 \\
\hline 31 & Silvya Ayu Harahap & 40 & 72 & 90 & 95 & 80 \\
\hline 32 & Susan Sri Diana Kurniawan & 40 & 72 & 80 & 95 & 80 \\
\hline 33 & Syifa Hauna Nurafifah & 40 & 72 & 77 & 90 & 80 \\
\hline \multirow[t]{3}{*}{34} & Wafa Noer Afifah & 40 & 75 & 90 & 95 & 80 \\
\hline & Jumlah & 1660 & 2588 & 2979 & 3211 & 2830 \\
\hline & Rata-rata & 48.8 & 76.12 & 87.62 & 94.44 & 83.24 \\
\hline
\end{tabular}

Dari tabel 3 diperoleh nilai rata-rata dari hasil praktik peserta didik bahwa pada hasil siklus ke 1 sebesar 76.12, siklus kedua sebesar 87.62, dan siklus ketiga sebesar 94.44, hal ini memberikan gambaran bahwa tingkat pencapaian hasil dari nilai rata-rata praktik mengalami kenaikan. sedangkan perolehan hasil belajar peserta didik dari sebelum diberi tindakan pada siklus kesatu sebesar 48.8 menjadi 83.24 pada siklus ketiga. Dengan kata lain, peserta didik mengalami peningkatan daya serap yang dibuktikan dengan semakin bertambahnya peserta didik yang mencapai ketuntasan minimum yaitu 72 . 


\section{KESIMPULAN}

Dari hasil penelitian ini dapat disimpulkan bahwa dengan menggunakan metode pengajaran yang tepat yaitu menggunakan model rancang bangun lego jadi lebih menarik dan tidak cenderung membosankan siswa, hal ini dapat dilihat dari hasil perolehan aktivitas peserta didik dari 2.24 pada kegiatan siklus ke 1 naik menjadi 3.18 pada siklus ke 3. Pemahaman konsep titik berat dengan menggunakan model rancang bangun lego diperoleh hasil sebesar
76.12 pada siklus 1 naik menjadi 94.44 pada siklus 3, hal ini dapat dikatakan bahwa ada keterkaitan yang signifikan antara perolehan hasil praktik dengan aktivitas peserta didik, sehingga perolehan pemahaman konsep yang baik dan benar dapat tercapai. Adanya kenaikan hasil belajar peserta didik sebesar 83.24, hal ini dapat dikatakan bahwa daya serap peserta didik baik karena dapat dibuktikan dengan hasil ketuntasan peserta didik yang sudah memenuhi standar ketuntasan yaitu 72 .

\section{DAFTAR PUSTAKA}

Arends, R. I. (2007). Learning To Teach. New York: McGraw Hill Companies, Inc.

Aunurrahman. (2009). Belajar dan Pembelajaran. Bandung: Alfabeta.

Badudu J. S., \& Zain, S. M. (1996). Kamus Umum Bahasa. Indonesia. Jakarta: Pustaka Sinar Harapan.

Dahar, W. R. (1986). Pengelolaan Pelajaran Kimia. Jakarta: Karunia.

Ruseffendi. (1998). Statistika Dasar Untuk Penelitian Pendidikan. Bandung: IKIP Bandung Press.

Sanjaya, W. (2009). Strategi Pembelajaran Berorientasi Standar Proses Pendidikan. Jakarta: Prenada.

Savery, J. R. (2006). Overview of Problem-based Learning: Definitions and Distinctions. Interdisciplinary Journal of Problem-Based Learning, 1(1).

Schmit, H. G., \& Moust, J. H. C. (2000). Factors Affecting Small-Group Learning: A Review Of The Research. In D. H. Evensen, \& C. E. Hmelo (Eds.), Problem-Based Learning: A Research Perspective On Learning Interactions.

Slameto. (2003). Belajar dan Faktor-Faktor yang Mempengaruhinya. Jakarta: PT. Rineka Cipta

Sudjana, N. (1989). Dasar - dasar Proses Belajar Mengajar. Bandung: Sinarbaru.

Zohar, A. (1994). The effect of Biology Critical Thinking Project in the Development of Critical Thinking. Journal of Research in Science Teaching, 31(2), 163-196. 